\title{
O ENSINO DO EMPREENDEDORISMO PARA ALUNOS DE CURSOS SUPERIORES TECNOLÓGICOS EM LOGÍSTICA - UM RELATO DE EXPERIÊNCIA
}

\section{ENTREPRENEURSHIP EDUCATION FOR STUDENTS OF HIGHER EDUCATION IN LOGISTICS TECHNOLOGY - AN EXPERIENCE REPORT}

Leandro Gonçalves Martins ${ }^{1}$

\section{RESUMO}

O ensino do empreendedorismo como disciplina em cursos superiores tecnológicos em logística é o objeto de estudo deste artigo, que relata a experiência de um docente no ensino do tema ao longo de dois anos. $\mathrm{O}$ artigo apresenta quais foram os principais conteúdos abordados e as experiências vividas pelo professor. Os resultados mostram que a definição de uma proposta pedagógica possa ser importante para melhorar a qualidade das aulas desse tema.

Palavras-chave: Educação empreendedora. Ensino superior. Prática docente. Logística. Empreendedorismo.

\section{ABSTRACT}

The entrepreneurship education as a discipline in higher education technology courses in logistics is the object of this article, which describes the experience of a teacher in teaching the topic over two years. The article presents the main content covered, and the experiences lived by the teacher. The results suggest that the definition of a pedagogical proposal might be important to improve the quality of the subject lessons.

Keywords: Entrepreneurial Education. Higher Education. Teaching practice. Logistics. Entrepreneurship.

\section{INTRODUÇÃO}

No papel de administrador de empresas, vejo o cenário atual brasileiro favorável para o crescimento de novas oportunidades de negócios. Enquanto docente universitário me deparo diariamente com alunos questionando se a única opção para eles, enquanto profissionais para o mercado de trabalho, seria ingressar em uma empresa e traçar um plano de carreira.

\footnotetext{
${ }^{1}$ Possui graduação em Administração com ênfase em Marketing pela Universidade Santa Cecilia (2004). Pósgraduado MBA em E-management pela Fundação Getúlio Vargas - FGV (2006). Mestre em Educação pela Universidade Católica de Santos - Unisantos (2015) - Linha de Pesquisa: Formação e Profissionalização Docente - Bolsista Capes. Atualmente é professor da ESAMC Santos, Centro Paula Souza - Fatec Rubens Lara Santos/SP e da Universidade Paulista - UNIP - Campus Santos. Email: admleandrogm@gmail.com
} 
Nos últimos anos, dentro e fora da sala de aula, encontro alunos ou ex-alunos que escolheram uma opção diferente de seus pares: o empreendedorismo, ou seja, abriram seu próprio negócio.

Diante deste cenário me questiono: até que ponto a universidade vem ajudando na formação de jovens empreendedores? De que forma a disciplina empreendedorismo, nos cursos superiores, vem contribuindo nesse sentido formativo?

O ensino do empreendedorismo é um grande desafio para qualquer tipo de aluno. Essa disciplina possui um arcabouço de conteúdo para ser apresentado com o intuito de incentivar os alunos a refletirem sobre a prática de empreender, seja montando seu próprio negócio, ou mesmo com atividades intraempreendedoras nas empresas onde já atuam.

\section{OBJETIVO}

Apresentar um relato de experiência de um professor universitário na docência da disciplina "Empreendedorismo" para os cursos superiores tecnológicos em logística.

\section{CONTEXTO DO EMPREENDEDORISMO}

Peter Drucker é mundialmente conhecido por sua enorme contribuição acadêmica nas disciplinas ligadas a administração. De acordo com Drucker (1985, p. 143), "Most of what you hear about entrepreneurship is all wrong. It's not magic; it's not mysterious; and it has nothing to do with genes. It's a discipline and, like any discipline, it can be learned”. Essa ideia corrobora com o sentido de que o tema pode ser ensinado nas universidades.

O empreendedorismo vem se tornando uma das práticas mais estudadas pelas grandes economias mundiais nos últimos anos. O modelo capitalista em que vivemos exige o surgimento de novas fontes de produtos, serviços e, consequentemente, renda. Dornelas $(2009$, p. 7$)$ apresenta a importância desse conceito quando afirma:

O empreendedorismo vem se mostrado um grande aliado do desenvolvimento econômico, pois tem dado suporte à maioria das inovações que têm promovido esse desenvolvimento. As nações desenvolvidas têm dado especial atenção e apoio às iniciativas empreendedoras, por saberem que são a base do crescimento econômico, da geração de emprego e renda.

Cruz e Cardoso (2012, p. 78) ainda complementam a discussão sobre o papel do empreendedorismo como elemento importante da sociedade moderna ao defenderem que 
invariavelmente o empreendedorismo é tido como sinónimo de aumento de valor social, partindo-se, sem grande discussão, de duas premissas na análise do fenómeno: i) o empreendedorismo é um comportamento que cria valor social; ii) a oferta de empreendedores não é rígida, pois o comportamento empreendedor pode ser ensinado.

Já na década de 40, Schumpeter (1942) anunciava que o empreendedor tinha a função de "destruir a ordem econômica" de forma criativa, incorporando inovações e novas tecnologias à sociedade, dessa forma contribuindo na substituição de produtos e processos obsoletos.

No entanto o que ainda encontramos no Brasil, na maior parte, são iniciativas de empreendimentos para subsistência, ou seja, como fonte de renda complementar para a família. Pequenos comércios, venda de alimentos, prestadores de serviços na área de estética, são os negócios com maior abertura no país. Como Dornelas (2009, p. 8) explica:

São negócios, em sua maioria, informais, focados no momento presente, sem planejamento, sem visão de futuro, sem a identificação de oportunidades e nichos de mercado, sem o comprometimento com o crescimento e com o desenvolvimento econômico.

O relatório executivo apresentado pela Global Entrepreneurship Monitor (Sebrae, 2012) é um documento produzido no Brasil com a parceria do Instituto Brasileiro da Qualidade e Produtividade (IBQP), juntamente com o Serviço Brasileiro de Apoio às Micro e Pequenas Empresas (SEBRAE) e com a Fundação Getúlio Vargas (FGV-EAESP). Neste documento encontram-se informações importantes que descrevem o atual perfil do empreendedor brasileiro. Destaca-se no relatório que nos novos empreendimentos, aqueles com menos de um ano de abertura, $82,7 \%$ dos empreendedores não possuem ensino superior completo.

O SEBRAE realiza ainda no Brasil diversos projetos e ações para profissionalizar os empreendimentos brasileiros, levando assim o conhecimento dessas informações às universidades de todo o país. Um exemplo interessante é o edital de chamada pública SEBRAE - UCE No 001/2013 (Sebrae, 2013, p. 2) onde, encontra-se o objetivo de

selecionar e apoiar, técnica e financeiramente, propostas de Parceria com Instituições de Ensino Superior - IES, com vistas à promoção da Educação Empreendedora nas Instituições de Ensino Superior, [...] com orientações básicas, parcerias com as IES, estrutura, linhas de ação e operacionalização/gestão, julgamento das propostas, execução, monitoramento e avaliação. 
Este tipo de iniciativa pode gerar um impacto positivo dentro das universidades brasileiras, criando um maior interesse por parte dos estudantes em empreender seu próprio negócio dentro das mais diversas áreas do conhecimento.

\section{MÉTODO}

\section{PARTICIPANTES}

Foram quatro turmas diferentes, mas todas do mesmo curso superior tecnológico de logística. No total, participaram aproximadamente 120 alunos, com faixa etária entre 18 e 42 anos. Todas as turmas foram do período noturno. Os alunos residiam nas cidades de Santos, São Vicente, Praia Grande, Cubatão ou Guarujá no estado de São Paulo. Cerca de 40\% dos alunos já atuavam na área logística quando cursaram a disciplina empreendedorismo.

\section{PERÍODO E LOCAL}

A experiência do ensino de empreendedorismo, neste caso em particular, realizou-se nos anos de 2012 e 2013, em uma universidade privada, localizada na cidade de Santos/SP. A instituição possui três campus diferentes na cidade, mas os alunos do curso de logística estavam no mesmo prédio. As salas de aula eram equipadas com 50 carteiras universitárias, quadro verde como lousa e aparelhadas com ar condicionado. Nenhuma das salas possuía equipamentos de projeção de vídeo ou som instalados.

\section{ESTRUTURA DAS AULAS}

As aulas tinham em média 1,5 horas semanais, perfazendo um total de 30 horas semestrais. O conteúdo proposto da disciplina era: 1) Habilidades do empreendedor; 2) Identificação de oportunidade; 3) Intraempreendedorismo; 4) Fatores críticos de sucesso; 5) Análises de estudos de caso; 6) Linhas de financiamento; 7) Aspectos gerais do plano de negócios.

Cada um dos pontos mencionados acima foram apresentados em aulas expositivas, ou seja, o professor apresentava na lousa uma série de conceitos-chave sobre os temas. Os últimos 15 minutos de cada aula eram abertos para dúvidas não só da disciplina, mas principalmente sobre o ato de empreender e montar o próprio negócio, além de discussões diversas sobre o tema. 
O professor, dentro do seu processo de ensino, utiliza-se dos meios que acredita ser necessário para transmitir seus conhecimentos, seja qual for a disciplina. Conforme nos orienta Abdalla (2006, p. 38-39, grifo da autora):

O que percebemos é que estamos envolvidos em uma luta propriamente simbólica/ideológica: ora, procuramos impor a nossa visão de mundo conforme nossos interesses; ora, reproduzimos o que nos é imposto; ora, tentamos eufemizar nossas lutas e compor com os pares um campo de possibilidades, de produções culturais.

Desse modo, é possível observar que o docente, ao transmitir seus conhecimentos sobre empreendedorismo, passa sua visão de mundo. Quando o mesmo docente apresenta o conteúdo definido pela ementa da instituição, ele realiza o que lhe é imposto. No momento em que ele discute junto com seus alunos, que estão se qualificando para exercerem suas funções na área de logística, o professor compõe um vasto campo de possibilidades.

Essas possibilidades podem surgir das mais diversas necessidades dos seus alunos. Ao solicitar a participação dos mesmos no final de cada aula, o professor estimula o processo de transformação. Mais uma vez, Abdalla (2006, p.26) auxilia de maneira importante na construção dessa visão ao afirmar que "com efeito, quando expressamos uma necessidade, de forma consciente, retratamos a realidade. Mas, por outro lado, podemos introduzir, também, uma intenção de ação a fim de transformar as condições existentes". Este era um dos objetivos das aulas: gerar reflexão sobre o ser empreendedor, suas necessidades e transformações.

Dentro do conteúdo definido para a disciplina, o tema 1 - habilidades do empreendedor - tinha por objetivo apresentar as principais habilidades que este profissional necessita para exercer suas atividades. Nobre, Tobias e Walker (2011, p. 416) definem habilidade como "algo que está relacionado à capacidade de agir mental, física, financeira, legal, jurídica e institucionalmente, entre outras formas". Neste artigo, habilidade e competência possuem o mesmo sentido. Dessa forma, o pensamento de Perrenoud (2000, online) melhor explica essa ideia:

Competência é a faculdade de mobilizar um conjunto de recursos cognitivos (saberes, capacidades, informações etc) para solucionar com pertinência e eficácia uma série de situações. [...] Os seres humanos não vivem todos as mesmas situações. Eles desenvolvem competências adaptadas a seu mundo. A selva das cidades exige competências diferentes da floresta virgem, os pobres têm problemas diferentes dos ricos para resolver. Algumas competências se desenvolvem em grande parte na escola. Outras não. 
O tema 2 - identificação de oportunidades - apresentava como objetivo auxiliar os alunos na busca pessoal de novas chances para se abrir um negócio. A inovação e a criatividade foram estimuladas neste ponto com o objetivo de ampliar a visão dos alunos diante das possibilidades do mercado.

Sternberg (2000) em suas pesquisas sobre criatividade identificou algumas características das pessoas que as adotam como estilo de vida: 1) os problemas são redefinidos por essas pessoas, que buscam formas diferentes para solucioná-los; 2) sabem identificar dentro das suas ideias aquelas que podem trazer um valor real para suas vidas; 3 ) sabem defender suas ideias e até mesmo "vende-las" para outras pessoas; 4) apesar da sabedoria que possuem, reconhecem que o conhecimento adquirido ou desenvolvido deve ser compartilhado.

No tema 3 - Intraempreenderorismo - a proposta era proporcionar aos alunos a reflexão sobre a possibilidade de serem empreendedores dentro das empresas onde já atuam, aproveitando as competências discutidas no tema anterior. Rogers (2011, p. 306) conceitua intraempreendedorismo como "o espírito e o ato de empreendedorismo no ambiente corporativo". Também conhecido por empreendedorismo interno, Barini Filho (2005, p. 29) complementa a importância desse assunto ao afirmar que

o empreendedorismo interno pode ser uma estratégia inovadora para assegurar maior competitividade e crescimento qualitativo, com contínua adaptação. [...] Pela capitalização da capacidade empreendedora dos profissionais pertencentes aos quadros da organização, podem-se adotar estratégias de mercado mais competitivas e eficazes, assegurando a sobrevivência no longo prazo.

Na sequência, o item 4 - fatores críticos de sucesso (FCS) - foram discutidos pontos essenciais para um resultado eficiente em um novo empreendimento. Diversos autores (DANIEL, 1961; LEIDECKER E BRUNO, 1984; KING E BURGESS, 2006) definem os FCS como sendo os fatores que determinam as forças e fraquezas que uma organização deveria adotar para medir suas vantagens em relação aos seus concorrentes. Esses fatores são as características que, quando devidamente estruturadas, podem ter grande impacto para o sucesso de uma instituição em uma determinada área de atuação. Entretanto não devem ser analisados de forma estanque e individualista, mas sim de modo mais amplo, avaliando como esses fatores influenciam no atual desempenho da empresa e em seus processos de melhoria na produtividade. 
Após a apresentação e discussão desses quatro primeiros itens, foi proposto aos alunos duas aulas para análise de dois estudos de casos, conforme definido no item 5. Alves Mazzotti (2006, p. 640-641) explica a diferença entre os tipos de estudo de caso:

Os estudos de caso mais comuns são os que focalizam apenas uma unidade: um indivíduo (como os "casos clínicos" descritos por Freud), um pequeno grupo (como o estudo de Paul Willis sobre um grupo de rapazes da classe trabalhadora inglesa), uma instituição (como uma escola, um hospital), um programa (como o Bolsa Família), ou um evento (a eleição do diretor de uma escola). Podemos ter também estudos de casos múltiplos, nos quais vários estudos são conduzidos simultaneamente: vários indivíduos (como, por exemplo, professores alfabetizadores bem-sucedidos), várias instituições (diferentes escolas que estão desenvolvendo um mesmo projeto), por exemplo.

Para as aulas de empreendedorismo, foram adotadas as análises de duas instituições: Bauducco e Boticário, e seus respectivos fundadores, Massimo Bauducco e Miguel Krigsner. Em cada estudo de caso, foi apresentada uma breve descrição da história da empresa e dos seus fundadores. Em seguida, foram discutidos os seguintes pontos com os alunos:

a) Quais características ou habilidades empreendedoras você consegue encontrar nos fundadores das empresas analisadas?

b) Quais podem ter sido os FCS nesses empreendimentos estudados?

c) Se você fosse um funcionário administrativo em uma dessas empresas, qual sugestão de inovação você daria?

No item 6 - linhas de financiamento - o objetivo central estava em apresentar quais as principais linhas de crédito disponíveis no Brasil para financiamento de máquinas, equipamentos e capital de giro. Neste artigo, a definição de financiamento está ligada a ideia de crédito que, segundo Camargos et al (2010, p. 336) pode ser definido

pela cessão temporária de recursos a terceiros, mediante remuneração (juros) cobrada ao devedor pelo seu uso, que pode ser concedido por vários tipos de empresas e para uma variada gama de finalidades, com destaque para o segmento bancário, que atua como agente intermediador das captações e aplicações de recursos na economia, sendo regulado por normas estabelecidas pelas autoridades monetárias.

Ressalta-se ainda que no Brasil, o acesso ao crédito para os microempresários ainda não é suficiente. Novamente, Camargos et al (2010, p. 335) contribui na apresentação desse cenário ao afirmar que "o volume de crédito concedido ao financiamento das atividades 
produtivas é ainda muito aquém do necessário, isso sem mencionar as elevadas taxas de juros e de spread bancário praticados na economia brasileira”.

Ainda assim, diante do escasso número de linhas de crédito para os pequenos empresários, nas aulas destinadas a esse tema, foram apresentadas as principais linhas de crédito concedidas na época, principalmente as ofertadas pelos bancos públicos. Destaca-se as linhas de financiamento com subsídios governamentais, em particular provenientes do banco nacional do desenvolvimento (BNDES).

Para finalizar o conteúdo proposto para a disciplina empreendedorismo, o item 7 tratou sobre os aspectos gerais do plano de negócios que, de modo geral, pode ser entendido como

um documento preparado pelo empreendedor em que são descritos todos os elementos externos e internos relevantes para o início de um novo empreendimento. É com frequência uma integração de planos funcionais, como os de marketing, de finanças, de produção e de recursos humanos (Hisrich, Peters, Shepherd, 2009, p. 219).

Contudo, nas aulas esse conceito foi ampliado, sugerindo que o plano de negócios também poderia ser adotado para outras finalidades em uma empresa ou não, conforme explica Finch (2006, p. 126):

Um plano de negócios é uma ferramenta administrativa essencial para auxiliar a gerir todos os tipos de organizações, variando desde empresas, passando por instituições de caridade e até organizações do setor público. Não serve apenas para negócios que estão se organizando mas também para aqueles que já se encontram estabelecidos. O texto do plano é tão importante para um empreendedor como também para uma divisão de uma companhia multinacional ou uma administração hospitalar.

Nas aulas reservadas para esse tema, foram apresentados os elementos constituintes de um plano de negócio com os seguintes capítulos: capa, sumário executivo, descrição da empresa, descrição dos produtos e serviços, análise da estratégia, análise de mercado, plano de marketing, plano de recursos humanos, plano financeiro e parecer final. Em cada um desses tópicos os alunos visualizaram exemplos de empresas reais.

\section{RESULTADOS E CONSIDERAÇÕES FINAIS}

"No Brasil, o professor Ronald Degen foi o primeiro a introduzir um curso de empreendedorismo, com o foco na criação de negócios, em 1981. A disciplina foi ministrada em um curso de especialização [...] da Fundação Getúlio Vargas.” (Lavieri, 2010, p. 8). Esse 
posicionamento histórico mostra que no país, o ensino do empreendedorismo é relativamente recente. Com pouco mais de 30 anos desde quando o tema foi introduzido no meio universitário, percebe-se que muito ainda precisa ser definido e estudado.

Ao longo das aulas, com diferentes alunos, algumas dificuldades se repetiam: não entendimento ou ainda não aceitação de que o empreendedorismo pode ser um caminho para o recém-formado no nível superior; desconhecimento de assuntos legais quanto da abertura de uma empresa ou para concessão de crédito junto às instituições bancárias; inaptidão em criar ou inovar produtos, serviços ou técnicas de trabalho; entre outras.

Destaca-se o interesse por parte dos alunos, de todas as turmas, nos estudos de caso. Os alunos discutiram as habilidades que os empreendedores analisados desenvolveram para conquistar o sucesso em suas empresas. Por outro lado, quando solicitada a participação dos alunos para propor ideias de melhorias nas organizações estudadas, as sugestões ficaram limitadas aos atuais produtos já ofertados. Poucos alunos conseguiram sugerir a criação de um novo produto ou serviço.

Percebe-se ainda que as universidades brasileiras pouco incentivam seus alunos por esse caminho. $\mathrm{O}$ ensino dos temas relacionados à administração de empresas pode ser direcionado para a gestão de pequenas empresas, inclusive na área da logística empresarial. Drucker $(2005$, p. 23) já falava sobre isso na década de 90 quando afirmava:

[...] estamos aprendendo que a Administração pode ser tanto mais necessária e também ter maior impacto sobre a pequena organização empreendedora do que na grande empresa "administrada". Acima de tudo, a Administração, conforme sabemos agora, tem tanto a contribuir para a empresa empreendedora nova, quanto para a empresa "administrativa" existente.

Planejar e executar um projeto pedagógico para o ensino do empreendedorismo no nível superior pode não ser uma tarefa fácil, mas alguns pontos precisam ser definidos e estimulados ao longo das aulas, conforme orienta Andrade (2009, p. 13):

Organizar uma proposta pedagógica comprometida com o empreendedorismo exige a adoção de estratégias que favoreçam e incentivem atitudes e posturas como: autonomia, iniciativa, autovalorização, ética, criatividade, cidadania, liderança, diálogo, participação, desenvolvimento de projetos, resolução de problemas, boa utilização da informação e dos recursos, inovação e pioneirismo.

Dessa forma, é possível concluir que não se trata de um conteúdo qualquer, mas sim de caráter formativo e profissionalizante. O importante talvez seja ampliar a visão dos 
estudantes universitários, através de estudos e debates, mostrando os caminhos que eles podem percorrer ao abrir o seu próprio negócio. Como sugestão para futuras pesquisas, seria interessante analisar o desempenho dos alunos de outros cursos superiores tecnológicos dentro do ensino do empreendedorismo, e assim expandir a analise sobre a docência desse tema.

\section{REFERÊNCIAS}

ABDALLA, Maria de Fátima Barbosa. O senso prático de ser e estar na profissão. São Paulo: Cortez, 2006.

ALVES-MAZZOTTI, Alda Judith. Usos e abusos dos estudos de caso. Cadernos de Pesquisa, v. 36, n. 129, p. 637-651, set./dez. 2006.

ANDRADE, Rosamaria Calaes de. Introdução: Empreendedorismo - Um Novo Passo em Educação. In: ANDRADE, Rosamaria Calaes de. (Org.); ACÚRCIO, Marina Rodrigues Borges. (Coord.). O empreendedorismo na escola. Porto Alegre / Belo Horizonte: Artmed / Rede Pitágoras, 2009.

BARINI FILHO, Ulrico. Desenvolvimento de competência empreendedora em organizações de negócio - o caso Odebrecht. In: VELOSO, Elsa; TREVISAN, Leonardo. (Org.). Produtividade e ambiente de trabalho: gestão de pessoas e carreiras. São Paulo: Editora Senac São Paulo, 2005. p. 25-48.

CAMARGOS, Marcos Antônio de et al. Fatores condicionantes de inadimplência em processos de concessão de crédito a micro e pequenas empresas do Estado de Minas Gerais. Rev. adm. contemp. [online], Curitiba, vol.14, n.2, art. 8, pp. 333-352, Mar./Abr. 2010.

CRUZ, José Neves; CARDOSO, Carla Sofia. O empreendedorismo e o ambiente jurídico e institucional. Economia Global e Gestão. Lisboa, v. 17, n. 1, abr. 2012.

DANIEL, B. R. Management information crisis. Harvard Business Review, p. 111-121, 1961.

DORNELAS, José Carlos Assis. Empreendedorismo corporativo. 2. ed. Rio de Janeiro: Elsevier, 2008.

DRUCKER, P. Innovation and Entrepreneuship: Practices and Principles. Harper, Nova York, 1985. 
DRUCKER, P. Inovação e espírito empreendedor. São Paulo: Pioneira Thomson Learning, 2005.

FINCH, Brian. Como redigir um plano de negócios. Tradução de Henrique Amat Rêgo Monteiro. 3. ed. São Paulo: Clio Editora, 2006.

HISRICH, Robert D.; PETERS, Michael P.; SHEPHERD, Dean A. Empreendedorismo. 7. ed. São Paulo: Bookman, 2009.

KING, S. F.; BURGESS, T. F. Beyond critical success factors: a dynamic model of enterprise system innovation. International Journal of Information Management, v. 26, n. 1, p. 59-69, 2006.

LAVIERI, Carlos. Educação... empreendedora? In: LOPES, Rose Mary A. (Org). Educação empreendedora: conceitos, modelos e práticas. Rio de Janeiro: Elsevier; São Paulo: Sebrae, 2010.

LEIDECKER, J. K.; BRUNO, A. V. Identifying and using critical success factors. Long Range Planning, London, v. 17, p. 23, 1984.

NOBRE, F. S.; TOBIAS, A. M.; WALKER, D. S. Uma Visão da Empresa Baseada em Habilidades. RAC, Curitiba, v. 15, n. 3, art. 3, pp. 413-432, Maio/Jun. 2011.

PERRENOUD, P. Construindo competências (entrevista de Paola Gentille e Roberta Bencini). Revista Nova Escola (Brasil), pp. 19-31. Set. 2000.

ROGERS, Steven. Finanças e estratégias de negócios para empreendedores. 2. ed. Porto Alegre: Editora Bookman, 2011.

SCHUMPETER, J. A. Capitalismo, socialismo e democracia. Rio de Janeiro: Zahar, 1942.

SEBRAE. Serviço Brasileiro de Apoio às Micro e Pequenas Empresas. Relatório Executivo. Global Entrepreneurship Monitor. Empreendedorismo no Brasil. Disponível em: < http:// bis.sebrae.com.br/GestorRepositorio/ARQUIVO

S_CHRONUS/bds/bds.nsf/9696c98c23d137fd0d8af1300d9742b0/\$File/4226.pdf $>$. Acesso em: 10 julho 2013.

SEBRAE. Serviço Brasileiro de Apoio às Micro e Pequenas Empresas. Edital de chamada pública SEBRAE - UCE No01/2013. Brasília. 2013. Disponível em: $<$ http:/gestaoportal.sebrae.com.br/customizado/sebrae/institucional/chama das-de- 
projetos/resumo-das-chamadas/novo-background/ee-edital-com-ies.pd f $>$. Acesso em: 10 julho 2013.

STERNBERG, R.J. Identifying and developing creative giftedness. Roeper Review, pp. 60-64, 01 Dez. 2000.

RECEBIBO EM: 29/07/2013

APROVADO PARA PUBLICAÇÃO EM: 14/09/2015 